\title{
Nanosilver and its medical implications
}

\begin{abstract}
Nanosciences along with the emergence of nanobiotechnolgy and nanomedicine in the last few decades provided a number of opportunities for exploring the bactericidal and fungicidal activities of metal nanoparticles. In the present scenario silver in the form of nanoparticles are playing a major role in the field of Nanotechnology and Nano medicine, their unique size dependent properties make them superior and indispensable. The use of nanotechnology in the field of medicine could revolutionize the way we detect and treat damage to the human body and disease in the future, and many techniques only imagined a few years ago are making remarkable progress towards becoming realities. Silver nanoparticles have been synthesized through various routes in the laboratories in India and as well as many foreign research institutes. These routes can be chemical as well as biological.Nanotechnology has provided a number of nanoparticle-based therapeutics and diagnostic agents. Silver-impregnated wound dressings have the potential to reduce both bio burden and healing time.
\end{abstract}

Keywords: Silver, Chemical reduction, Biosynthesis, Nanoparticles, Nanosilver, Sol-gel process
Volume 2 Issue 5 - 2015

\author{
Mini Mishra,' Pratima Chauhan² \\ 'IDepartment of Environmental Science, University of Allahabad, \\ India \\ ${ }^{2}$ Depatment of Physics, University of Allahabad, India
}

Correspondence: Pratima Chauhan, Depatment of Physics, University of Allahabad, 211002 , India

Emailmungu167@yahoo.co.in

Received: September 30, 2015 | Published: December 08, 2015

\section{Introduction}

Nanoscience and nanotechnology have received much interest since last few decades and metal nanoparticles are at the leading edge of rapidly developing field of nanotechnology. The concept of nanotechnology was visualized in 1959 by the physicist Richard P. Feynman who got the Nobel Prize in this field. Nanoparticles can be defined as "particulate dispersion or solid particles with a size in the range of 10-1000 nm. One nanometer spans 3-5 atoms lined upon in a row. Nanoparticles are of great scientific interest as they are effectively a bridge between bulk materials and atomic or molecular structures .

It is basically science, engineering and technology conducted at the nanoscale which is about 1 to $100 \mathrm{~nm}$. The U.S. National Nanotechnology Initiative (NNI) defined it as understanding and control of matter At Dimensions between approximately 1and 100 nanometers where unique phenomenon enable novel application.$^{2}$ The substance in nano-regime exhibits a large number of new properties. The properties of substances in nanosize are entirely different from the corresponding bulk or atomic and molecular counterparts.

The word nanotechnology was firstly popularized by K. Eric Drexler in 1980s and he meant about building machines on the scale of molecules, a few nanometer wide motors, robot arms and even whole computer, for smaller than a cell. ${ }^{3}$ Nanotechnology since long time ago helping to considerably improve even revolutionize, many technology and industry sectors, Information technology, energy environmental science medicine, homeland security, food safety and transportation among many others.$^{4-7}$ Their unique sizedependent properties make them superior and indispensable in many areas ranging from electronics and communications, through optics, chemistry, energy and of course biology.$^{8-13}$

The advancement in the field of nanoscience has truly brought revolutionary changes in industrial, medicine, textile, food packaging and agriculture fields.${ }^{14-18}$ We all are very much aware of silver as an antimicrobial agent since time immemorial in the form of metallic silver, silver nitrate, silver sulfadiazine for the treatment of burns, wounds and several bacterial infections.$^{19-}$ ${ }^{24}$ After the flooding of a number of antibiotics, usage of silver for the treatment of bacterial infection reduced. Moyer introduced the use of $0.5 \%$ silver nitrate for the treatment of burns. He proposed that it possess antibacterial property against Staphylococcus aureus, Pseudomonasareuginosa, and Escherichia coli.$^{25-27}$ Silver nanoparticles also act as effective fungicide against common fungi including Aspergillus, Candida and Saccharomyces. ${ }^{28}$ The antifungal activity of silver nanoparticle has received less attention, yet some of the studies revealed that silver nanoparticles can be as effective for fungal strains as like that of bacterial strains. Ales Panacek et al. ${ }^{29}$ has examined effect of silver NPs on pathogenic strain of Candida spp. by determining the minimum inhibitory concentration, minimum fungicidal concentration and time dependency of yeast growth inhibition and concluded that silver nanoparticles exhibit high antifungal activity against Candida spp. at the concentration of $1 \mathrm{mg} / \mathrm{L}$ of Ag. Silver nanoparticles inhibit growth of yeast at very low concentration as compared to those of common antifungal. ${ }^{29}$ Virucidal effect of silver nanoparticles is still in closed envelops, however recently the antiviral effect of silver nanoparticles on the hepatitis $\mathrm{B}$ virus have been reported using a HepAD38 human hepatoma cell line. ${ }^{30}$ Although antiviral effect of silver nanoparticle has not been come in attention yet there are some of the evidences given by Humberto H Lara et al. ${ }^{30}$ Sun and colleagues showed that agNPs were superior to gold nanoparticles for cytoprotective activities towards HIV-1-infected helper cells. Nanosilver may interfere with the fusion of the viral membrane, inhibiting viral penetration into the host cell. Silver nanoparticles specifically refer to silver containing material with modified physicochemical properties due to their nanosized scale. Antimicrobial properties of silver nanoparticles are being exploited by many pharmaceutical companies for making antibiotics, used in biomedical applications.$^{31-33}$ The use of Silver nanoparticles in the field of medicine could revolutionize the way we detect and treat damage to the human body and disease in the future, and many techniques only imagined a few years ago are making remarkable progress towards becoming realities ${ }^{34}$ Hippocrates, the "father of medicine", advocated the sprinkling of silver powder on ulcers to expedite healing, and silver has been used since World War I (and continues to be used) in wound dressings. This rapidly developing field of nanoscience has raised the possibility of using therapeutic nanoparticles in the diagnosis and treatment of human cancers.$^{35}$ 


\section{Synthesis of Silver Nanoparticles}

Silver nanoparticles have been synthesized through an array of methods, e.g. spark discharging, electrochemical reduction, solution irradiating and cryochemical synthesis.$^{36-40}$ For the synthesis of nanoparticles, the first priority is to achieve large-scale production in an economical manner ${ }^{41}$ There are two main methods for the preparation of nanoparticles showing in Figure 1..$^{42}$

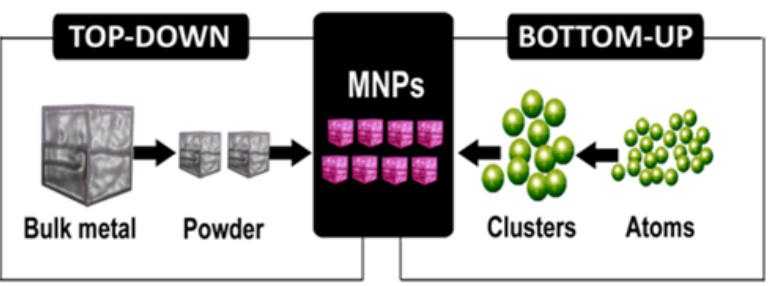

Figure I Two major synthesis process of metal nanoparticles.

a. Top-down approach via milling

b. Bottom-up approach via chemical processes

\section{Top down approach}

Top down approach is solely based on physical and microlithographic philosophy, in contrast to the other approach, where atomic or molecular units are used to assemble molecular structure, ranging from atomic dimensions up to supramolecular structure in nanometer range. It mainly involves mechanical/thermal cycle and yields:

I. Broad size distribution (10-1000nm)

II. Varied particle shape or geometry

III. Impurities

\section{Bottom-up approach}

Bottom-up approach is solely based upon chemical principles, it involves:

\section{Gas phase synthesis}
a. Pyrolysis
b. Inert gas condensation

\section{Liquid phase synthesis}

a. Solvothermal process

b. Sol-gel process

c. Micellar structure media

Vapor phase synthesis: Nanoparticles of wide range can be prepared by a variety of methods. Hahn presented a useful overview of gas-phase synthesis of nanocrystalline material. In vapor-phase synthesis, conditions are created where the vapor-phase mixture is thermodynamically unstable relative to formation of solid material to be prepared in nanoparticulate form.$^{43}$

Pyrolysis: In pyrolysis, vaporous precursor is forced through a hole or opening at high pressure and burned. The resulting solid in air is classified to recover oxide particles from byproduct gases.

Inert gas condensation: In this process solid material is heated to evaporate it into a background gas, and then the vapor is mixed with cold gas to reduce the temperature. This method is well suited for production of metal nanoparticles.

\section{Liquid phase synthesis}

Liquid-phase fabrication entails a wet-chemical route and involves the following processes:

Solvo thermal synthesis: In this method, precursors are dissolved in hot solvent (e.g., n-butyl alcohol). Solvents other than water can provide milder and friendlier reaction condition.

\section{Sol-Gel process}

The sol-gel process is a wet-chemical technique widely used in the field of material science and ceramic engineering; it involves the following steps:

i. Formation of stable sol solution

ii. Gelation via polycondensation or polyesterification

iii. Gel aging into solid mass

iv. Drying of gel to remove liquid phases

v. Dehydration at $8000^{\circ} \mathrm{C}$ to remove $\mathrm{M}-\mathrm{OH}$ group for stabilizing gel

vi. Densification and decomposition of gel at high temperature (T> $\left.8000^{\circ} \mathrm{C}\right)$

The precursor sol can be either deposited on a substrate to form a fi $1 \mathrm{~m}$, cast into a suitable container with the desired shape or used to synthesize powders (e.g., nanospheres).

\section{Synthesis in Structured Medium}

This is the mixing of two microemulsion carrying metal salt and reducing agent. Silver nanoparticles can be synthesized chemically by using different chemical like PVA, CTAB, NaBH4 as reducing agent and silver nitrate as substrate. It is common knowledge that the method of chemical reduction involves the reduction of relevant metal salts in the presence of a suitable protecting agent ${ }^{44-48}$ Reduction of relevant metal salts in the presence of a suitable protecting agent, reduction of relevant metal salts in the presence of a suitable protecting agent. The use of a strong reductant such as borohydride, resulted in small particles that were somewhat monodisperse, but controlling the generation of the larger particles became difficult ${ }^{49}$ The use of citrate, a weaker reductant, resulted in a slower reduction rate, but the size distribution was far from narrow.$^{50}$ The controlled synthesis of silver colloid particles was attempted using a two-step reduction process in order to control the particle size.

Recent era have explored critical role of microorganisms, and other biological entities such as extracts of different parts of the plants for the synthesis of metal nanoparticles. Green synthesis of metal nanoparticles is ecofreindly method without using harsh toxic and expensive chemicals. Biosynthesis of metallic nanoparticles using plant extract is a fabulous and emerging ecofreindly science of welldefined sizes, shapes and controlled monodisparity. Synthesis of nanoparticles using plant extract is very cost effective and therefore can be used as agar medium and transferring them to shoot of the plant in the same oxidation state. In this shoot these Ag atoms arrange themselves to form nanoparticles by joining themselves to form larger arrangements. Within use of Emblica officinalis fruit extract, as reducing agent, the extracellular synthesis of highly stable $\mathrm{Ag}$ and $\mathrm{Au}$ NPs has been achieved.$^{51}$ Achlypha indica leaf extract have produced silver nanoparticles had excellent antimicrobial activity against water borne pathogens like $E$. coli and $V$. cholera.$^{52}$ A diagrammatic presentation is given below in Figure 2 showing green synthesis of 
silver nanoparticle using plant extract.$^{53}$ There are number of plants and their parts which has been exploited for the biological synthesis of silver nanoparticles as listed in the Table 1.

Table I Different plants exploited for synthesis of silver nanoparticles

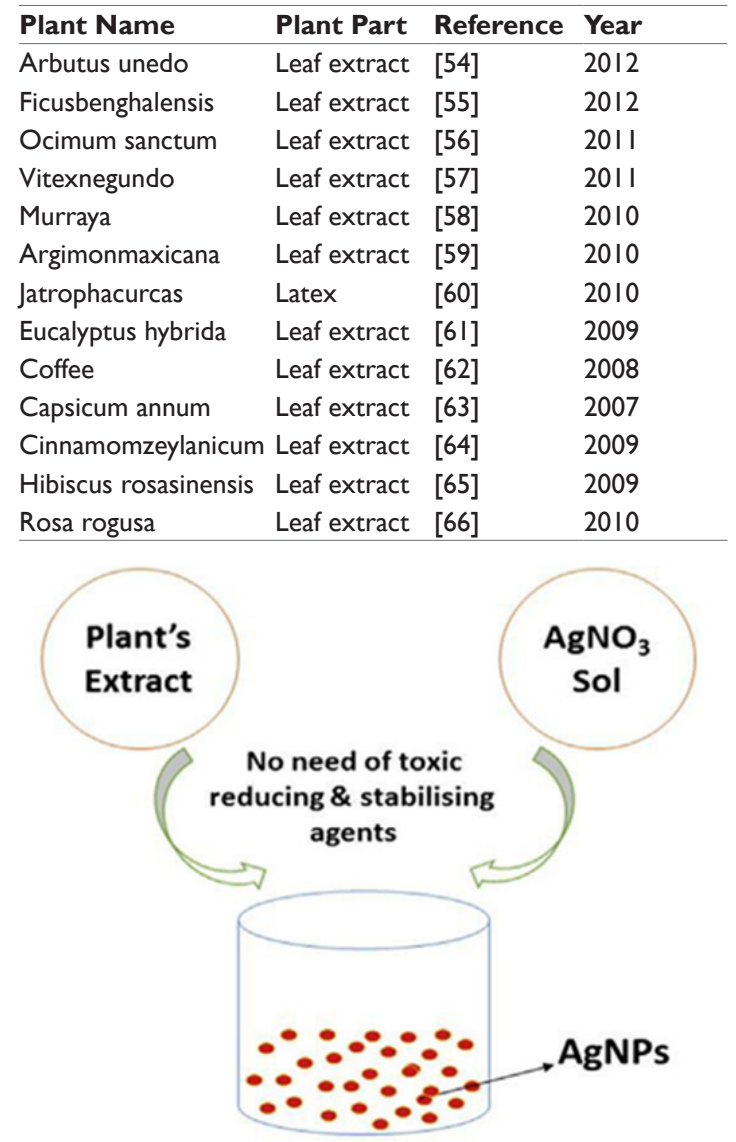

Figure 2 One pot green synthesis of silver nanoparticles.

Not only plants but other biological entities in the world have great potential to synthesize metal nanoparticles specifically silver in the nanorange have been fabricated using microoraganisms by many researchers. Among the microorganisms, prokaryotic bacteria have received the most attention in the area of bio-synthesis of nanoparticles. Bacteria involved in silver leaching have been reported to accumulate silver sulfide within their membrane.$^{66}$ the microbial reduction of water soluble $\mathrm{Ag}$ to $\mathrm{Ag} 0$ using an airborne bacteria (Bacillus sp.) have been corroborated by Nalenthiran Pugazhenthiran and his coworkers in the present atmosphere. ${ }^{67}$ The microbial synthesis of single crystals of silver with well-defined composition and shapes such as equilateral triangles and hexagons by the culture Pseudomonas stutzeri has been reported earlier ${ }^{68}$ The exact reaction mechanisms leading to the formation of silver nanoparticles by the silver resistant bacteria is yet to be elucidated. Nano-particle usually forms the core of nano-biomaterial. Aqueous silver ions when exposed to the fungus Fusarium oxysporum are reduced in solution, thereby leading to the formation of an extremely stable silver hydrosol ${ }^{69}$ Similarly fungus Verticillium can also reduces aquoues solution of silver nitrate to silver in nanometers [Priyamvada].${ }^{70}$ Extracellular biosynthesis of silver nanoparticles exploiting storage fungus Aspergillus niger was reported in 2008 by Gade end coworkers ${ }^{66}$ Silver nanoparticles in the size range of $2-5 \mathrm{~nm}$ were synthesized extracellular by a silvertolerant yeast strain MKY3, when challenged with $1 \mathrm{mM}$ soluble silver in the log phase of growth.$^{71}$
The organisms used in the synthesis of nanoparticles vary from simple prokaryotic bacterial cells to complex eukaryotes. Important steps are:

a. Selection of the best organism which shows enzyme activities and biochemical pathways.

b. Optimal condition for all growth and enzyme activity, e.g., nutrient, inoculums size, light, temperature and $\mathrm{pH}$ should be optimized.

c. Optimal reaction condition.$^{41}$

\section{Mechanism of Antimicrobial Activity of Silver}

The exact mechanism of the antimicrobial effect of silver as well as copper nanoparticles is not well known, however the three most common mechanism of antimicrobial activity proposed to date are.$^{72}$ Uptake of free silver nanoparticles followed by disruption of ATP production and DNA replication,

\section{a. silver nanoparticles and silver ions generation of ROS and}

\section{b. Silver nanoparticles direct damage to cell membranes.}

There are certain reports regarding mode of action of silver nanoparticles against pathogenic microbes. AgNPs interact with a wide range of molecular processes within microorganisms resulting in a range of effects from inhibition of growth, loss of infectivity to cell death which depends on shape, size, and concentration of AgNPs and the sensitivity of the microbial species. In Figure 3 action of silver nanoparticles towards cell membrane shows that the positive charge on the $\mathrm{Ag}+$ ion is crucial for its antimicrobial activity through the electrostatic attraction between the negatively charged cell membrane of the microorganism and the positively charged nanoparticles.$^{73}$ In contrast, Sondi \& Salopek Sondi reported that the antimicrobial activity of AgNPs on Gram-negative bacteria depends on the concentration of AgNPs and is closely associated with the formation of pits in the cell wall of bacteria; consequently, AgNPs accumulated in the bacterial membrane disturbing the membrane permeability, resulting in cell death.$^{74}$ Amro et al. ${ }^{75}$ suggested that metal depletion may cause the formation of irregularly shaped pits in the outer membrane and change membrane permeability, which is caused by the progressive release of lipopolysaccharide molecules and membrane proteins ${ }^{75}$

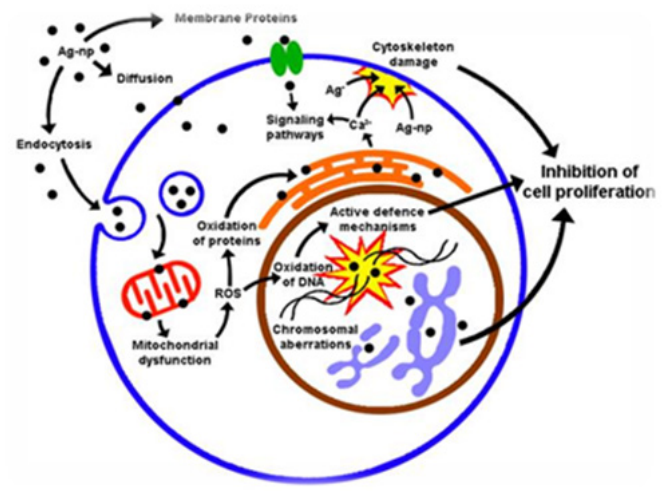

Figure 3 Action mechanism of silver nanoparticles on biological membrane.

\section{Medical applications of silver nanoparticles}

The medical properties of silver have been known for over 2,000 years. Since nineteenth century, silver-based compounds have been used in many antimicrobial applications.${ }^{76}$ As it is well known that silver nanoparticles are very small particles which measure not more than three or four atoms across, they are also versatile enough, and therefore they can be used in many types of medical procedures. Nano 
silver reacts cell changing the structures of membrane and damaging DNA. It is estimated that of all the nanomaterials in medical and healthcare sector, nanosilver application has the highest degree of commercialization.$^{77-79}$ Therefore, exposure to nanosilver in the body is becoming increasingly widespread and intimate. Consequently, silver in the form of nanoparticles has gained an increasing access to tissues, cells and biological molecules within the human body.$^{80}$ Silver nanoparticles are used for coating intraventricular catheter inside our body.

Recent Studies on new targeted silver nanoparticle contrast agents for early characterization of atherosclerosis and cardiovascular pathology at the cellular and molecular levels that might represent the next frontier for combining imaging and rational drug delivery to facilitate personalized medicine ${ }^{81}$ Today development of antimicrobial compounds having bactericidal potential against multidrug resistant bacteria is a priority area of research. In this concern M. K. Rai and coworker have studied bactericidal activity of silver nanoparticles against multi drug resistant bacteria. This Multifunctional Nano weapon can be used for the treatment of drug resistant microbes such as Pseudomonas aeruginosa, ampicillin resistant E. coli, erythromyces resistant Streptomyces aureus and Vancomycin resistant Staphylococcus aureus ${ }^{82}$ Silver nanoparticles ions have capacity to inhibit the bactericidal replication by binding and denaturing bactericidal DNA.$^{83}$

\section{Silver nanoparticles in drug delivery}

Nanoparticles have the efficiency to increase the solubility of poorly water-soluble drugs, accelerate the rate of reaction, increase drug half-life by reducing immunogenicity, increase specificity towards the target cell or tissue improve bioavailability, reduce the side effect of that particular medicine ${ }^{84}$ The primary goal for reason of nano-biotechnologies in drug delivery includes:

a. More specific drug targeting and delivery

b. Reduction in toxicity while maintaining therapeutic effects

c. Greater safety and biocompatibility and

d. Faster development of new safe medicine.$^{85}$

The nanosized drug can be formulated in less volume, so the single dose the patient has to take (daily dose $625 \mathrm{mg}$ of megestrol in $5 \mathrm{ml}$ of fluid) is reduced by the factor four compared to the oral solution available. ${ }^{85}$ There are two ways to employ nanoAg for bioimaging: Either incubated with cells and monitor their physical interactions and uptake or to functionalize the nano Ag surface with a biomolecule that binds specifically to sites on the cell membrane Silver nanoparticles can be used as effective tools for the advancement of drug delivery, medical imaging, and as diagnostic sensors as showing in the diagramme in Figure 4. Which clearly indicate the therapeutic agent, imaging agent and targeting moieties of silver nanoparticle ${ }^{82}$

\section{Silver nanoparticles in medicine}

Nanotechnology has been increasingly implemented in the area of health therapeutics in nanomedicine for the preservation and improvement of human health, using molecular tools and molecular knowledge of the human body. Today there is the utmost need for fabricating nanodevices for early detection and location of cancer at a molecular level, delivering anticancer drugs to the specific site and simultaneously determining their efficacy in reducing cancer load.$^{83-85}$ Nanotechnology will ring in the era of dental nanorobots, which find application in treating hypersensitive teeth.$^{86}$ and also in the identification and destruction of pathogenic bacteria residing in plaque, nanocomposites with nanofillers for enhanced durability and aesthetics, and impressions material with nanofillers for precise tissue detail ${ }^{87,88}$ The use of silver in nanosize scale seems to have reduced cellular toxicity but not antibacterial efficacy.

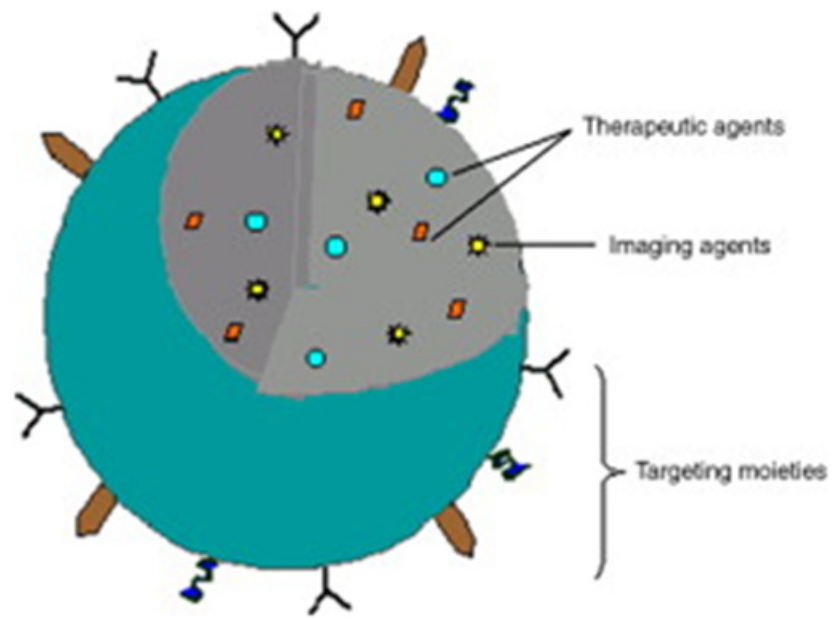

Figure 4 Multifunctional Silver NPs for therapeutics, diagnostics and imaging.

Various medicines and medical product have commercially been formulated by silver nanoparticles and used clinically worldwide for the treatment of serious ailment of human body ${ }^{89}$ The addition of AgNps to antibiotics has been shown to have synergistic effects against micro-organisms. Strydom et al also demonstrated that modification of silver sulphadiazine using dendrimer increased their anti-bacterial efficacy. Today many medicines and other medical products containing nanosilver are available in the market. Some of them are given in the Table 2 and are being extensively used in the hospitals and homes as well.$^{90}$

Table 2 Commercially available medical products containing Nanosilver

\begin{tabular}{|c|c|c|c|}
\hline Product & Company & Description & Clinical Uses \\
\hline Acticoat ${ }^{\mathrm{TM}}$ & Smith \& Nephew & $\begin{array}{l}\text { Nanocrystalline silver wound } \\
\text { dressing }\end{array}$ & $\begin{array}{l}\text { Dressing for a range of wounds including burns and ulcers; } \\
\text { prevents bacterial infection and improves wound healing. }\end{array}$ \\
\hline Silverline $®$ & Spiegelberg & $\begin{array}{l}\text { Polyurethane ventricular catheter } \\
\text { impregnated with NS }\end{array}$ & $\begin{array}{l}\text { Neurosurgical drain of CSF for hydrocephalus. Also can be } \\
\text { adapted for use as shunts. Antibacterial silver NP coating } \\
\text { prevents catheter-associated infections. }\end{array}$ \\
\hline SilvaSorb $®$ & $\begin{array}{l}\text { Medline Industries and } \\
\text { AcryMed }\end{array}$ & $\begin{array}{l}\text { Antibacterial products: hand gels, } \\
\text { wound dressings, cavity filler }\end{array}$ & $\begin{array}{l}\text { Wound dressings and cavity filler prevent bacterial } \\
\text { infection. Hand gels used to disinfect skin in clinical and } \\
\text { personal hygiene purposes. }\end{array}$ \\
\hline ON-Q SilverSoaker TM & I-Flow Corporation & $\begin{array}{l}\text { Silver-NP-coated catheter for drug } \\
\text { delivery }\end{array}$ & $\begin{array}{l}\text { Delivery of medication (e.g. local anesthetics or analgesics) } \\
\text { per-, peri- or post-operatively for pain management or for } \\
\text { antibiotic treatment. }\end{array}$ \\
\hline
\end{tabular}




\section{Silver nanoparticles in wound healing}

A number of wound dressings containing silver as an antibacterial have been cleared by the U.S. Food and Drug Administration (FDA).$^{91-94}$ Wound dressings containing silver sulfadiazine or silver nanomaterials may be used on external infections ${ }^{95-97}$ A 2012 systematic review found that silver containing dressings were no better than nanosilver containing dressings in treating burns.${ }^{97} \mathrm{Ag}$ based dressings are now available as a variety of fibers or polymeric scaffolds impregnated or coated with an Ag salt or metallic Ag in nanoparticulate form. They all exhibit fast and broad spectrum antibacterial activity against both Gram positive and negative bacteria .98

Recently, a trend toward the use of wound cover dressings that contain Ag has been evident, and today, a selection of foam, film, hydrocolloid, gauze, and dressings with Hydro fiber technology impregnated with $\mathrm{Ag}$ are commercially available.$^{99,100}$

Silver-impregnated wound dressings have the potential to reduce both bio burden and healing time. This can be clearly observed in the picture below in Figure 5. Here the wound dressed by any normal ointment used as control was healed in 7 days, whereas silver nanoparticles impregnated ointment healed the wound in 3 days.$^{28}$

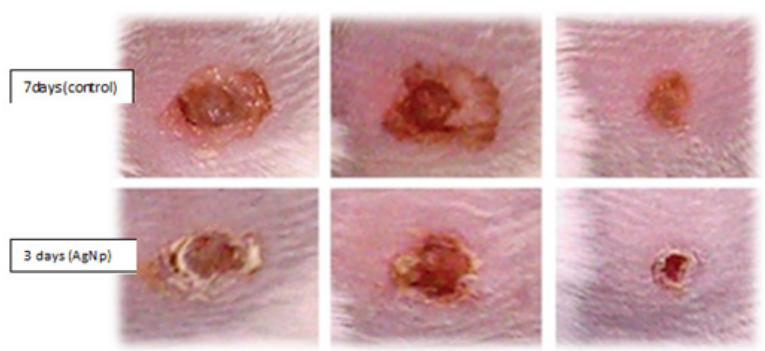

Figure 5 Progressive healing of wound with the application nanosized silver ointment.

\section{Nanosilver in cancer therapy}

Several investigators reported the anticancer activity of biosynthesized Silver NPs towards in vitro and in vivo systems.$^{101}$ Human epidermoid cancer cell line was targeted with folated silver dendrimer composite nanodevices and the labeled cancer cells were subsequently destroyed by the microbubbles generated through increased uptake of laser light energy by Ag Nps ${ }^{102}$ Tse presented a novel method to selectively destroy cancer cells.$^{103}$

\section{Nanosilver in medical diagnostics and therapeutics}

Early diagnosis of any disease condition is vital to ensure that early treatment is started and perhaps resulting in a better chance of cure. In terms of detecting cancer, $\mathrm{Au}-\mathrm{Ag}$ nanorods were used in a recent study as a nano platform for multivalent binding by multiple aptamers, so as to increase both the signal and binding strengths of the aptamers in cancer cell recognition. Nanosilver products are also employed to produce dual imaging/ therapy immune targeted nano shells to locate cancer cells and can absorb light and selectively destroy targeted cancer cells through photo thermal therapy.$^{104}$ The molecular assembly of aptamers on the nanorods was shown to lead to a 26-fold higher affinity than the original aptamer probes 63 . Thus, these nanorod-aptamer conjugates are highly promising for use in specific cell targeting, as well as having the detection and targeting ability needed for cell studies, disease diagnosis, and therapy.$^{105}$

The potential anti-inflammatory action of silver nanoparticles has been suggested in various studies described previously.$^{106}$ On the other hand, inflammation has been noted to play a significant part in the formation of post-operative adhesions. In animal models, we showed that intra-peritoneal injection of silver nanoparticles significantly reduced the degree of post-operative fibrous adhesions. The anti-inflammatory effects have also been substantiated in other inflammatory disease models by others. Taken together, it would suggest that silver nanoparticles can indeed reduce inflammation and its use in other inflammatory conditions is eagerly anticipated.$^{107}$

\section{Discussion and conclusion}

Silver has always been an excellent antimicrobial and has been used for the purpose for ages. The unique physical and chemical properties of silver nanoparticles Chemical and physical methods of silver nanoparticle synthesis were being followed over the decades, but they are found to be expensive and the use of various toxic chemicals for their synthesis makes the biological synthesis the more preferred option. Though bacterial, fungal, and plant extract sources can be used for nanosilver synthesis, the easy availability, the nontoxic nature, the various options available, and the advantage of quicker synthesis make plant extracts the best and an excellent choice for nanosilver synthesis only increase the efficacy of silver.

The most recent research has shown that nanoparticles can also be beautifully synthesized by using plant extract. After so much researches and studies on silver nanoparticles, it can be summarized that silver nanoparticles exhibit broad spectrum antimicrobial activities towards bacteria as well fungal sp. and also other microbes. The AgNPs have also found to be effective against many viral diseases. Silver Nanoparticles have really proven their potential applications in each and every field, such as in agriculture, where nanoparticles have shown the potential to replace insecticides and pesticides and are becoming a boon for curing a number of plant diseases, and are showing a revolutionary response in the field of biomedical applications in drug delivery, cancer therapy, dentistry and many more. Nanosilver is the most used nanoscale material in consumer products in Germany. According to the report of Federal Institute for Occupational Safety and Health (BAuA), 1040 biocidal products with (Nano) Silver are commercially manufactured.

\section{Acknowledgments}

We would like to acknowledge the academic section of university of Allahabad for providing library and internet facilities to scan the literature regarding the review, we are thankful to the central facilities of the department. Great vote of thanks to our lab mates who gave their precious ideas and valuable time to make this review worth. Financial support was provided by UGC fellowship and contingency.

\section{Conflicts of interest}

None.

\section{References}

1. Czajka R "Development of medical textiles". Fibers Text East Eur. 2005;13(1):13-15

2. Mihail C Roco "The Long View of Nanotechnology Development: The National Nanotechnology Initiative at 10 Years". In: Mihail C Roco et al. (Eds.), Nanotechnology Research Directions for Societal Needs in 2020. (Volume 1) Science Policy Reports, Springer p. 2011;1-28.

3. Eric Drexler K "Nanotechnology: From Feynman to Funding". Bulletin of Science Technology Society. 2004;24(1): 21-27.

4. Sheng-shan Bi, Lin Shi, Li-li Zhang "Application of nanoparticles in domestic refrigerators". Applied Thermal Engineering. 2008;28(14-15):1834-1843 
5. Rudolf G, Gröppel P, Volker M et al. "Application of Nanoparticles in Polymers for Electronics and Electrical Engineering". Particle \& Particle Systems Characterization. 2002;19(5):293-299.

6. Sawai J, Shoji S, Igarashi H et al. "Hydrogen peroxide as an antimicrobial factor in zinc oxide powder slurry". Journal of Fermentation and Bioengineering. 1998;86(5):521-522.

7. Miller J Beyond biotechnology: FDA regulations of Nanomedicine. Columbia Sci Technol Law Rev 2003;4:E5.

8. Moghimi SM, Hunter AC, Murray JC Nanomedicine: current status and future prospects. FASEB J. 2005;19(3): 311-330.

9. Roco MC Nanotechnology: convergence with modern biology and medicine. Curr Opin Biotechnol. 2003;14(3):337-346.

10. Gogos A, Knauer K, Bucheli TD Nanomaterials in Plant Protection and Fertilization: Current State, Foreseen Applications, and Research Priorities. J Agric Food Chem 2012;60(39): 9781-9792.

11. Whitesides GM Nanoscience, nanotechnology, and chemistry. Small. 2012'1(2):172-179.

12. Kyriacou SV, Brownlow WJ, Xu XH Using nanoparticle optics assay for direct observation of the function of antimicrobial agents in single live bacterial cells. Biochemistry. 2004;43(1): 140-147.

13. Langer R Biomaterials in drug delivery and tissue engineering: One laboratory's experience. Acc Chem Res. 2000;33(2):94-101.

14. Wagner V, Dullaart A, Bock AK et al. The emerging nanomedicine landscape. Nat Biotechnol. 2006;24(10):1211-1217.

15. Muller RH, Bohm BHL "Nanosuspensions. In: Muller RH, et al. (Eds.), "Emulsions and Nanosuspensions for the Formulation of Poorly Soluble Drugs. Stuttgart : Medpharm, pp. 1998;396.

16. Emerich DF, Thanos CG Targeted nanoparticle-based drug delivery and diagnosis. J Drug Target. 2007;15(3):163-183.

17. Esenaliev RO Radiation and nanoparticles for enhancement of drug delivery in solid tumors. PCT IntAppl WO 2000002590. 2000

18. Thote AJ, Gupta RB Formation of nanoparticles of a hydrophilic drug using supercritical carbon dioxide and microencapsulation for sustained release. Nanomedicine. 2005;1(1):85-90.

19. Sanpui P, Murugadoss A, Prasad PV et al. The antibacterial properties of a novel chitosan -ag-nanoparticles composite. Int J Food Microbiol. 2008;124(2):142-146.

20. Muangman P, Chuntrasakul C, Silthram S et al., Compar- ison of efficacy of $1 \%$ silver sulfadiazine and Acticoat for treatment of partialthickness burn wounds. J Med Assoc Thai. 2006;89(7):953-958.

21. Shrivastava S, Bera T, Roy A et al. Characterisation of enhanced antibacterial effects of novel silver nanoparticles. Nanotechnology. 2007;18(22):1-9.

22. Choi $\mathrm{O}, \mathrm{Hu} \mathrm{Z}$ Size dependent and reactive oxygen species related nanosilver toxicity to nitrifying bacteria. 2008;42(12):4583-4588.

23. Lansdown A. Silver in health care: antimicrobial effects and safety in use. Curr Probl Dermatol. 2006;33:17-34.

24. Dowsett C. The use of silver-based dressings in wound care. Nurs Stand. 2004;19(7):56-60.

25. Li WR, Xie XB, Shi QS, et al. Antibacterial effect of silver nanoparticles on Staphylococcus aureus. Biometals. 2011;24(1):135-141.

26. Birla SS, Tiwari VV, Gade AK, et al. Fabrication of silver nanoparticles by Phomaglomerata and its combined effect against Escherichia coli, Pseudomonas aeruginosa and Staphylococcus aureus", Lett Appl Microbiol. 2009;48(2):173-179.

27. Shahverdi AR, Fakhimi A, Shahverdi HR, et al. Synthesis and effect of silver nanoparticles on the antibacterial activity of different antibiotics against Staphylococcus aureus and Escherichia coli. Nanomedicine. 2007;3(2):168-171.

28. Rai M, Yadav A, Gade A. Silver nanoparticles as a new generation of antimicrobials. Biotechnol Adv. 2009;27(1):76-83.

29. Panácek A, Kolár M, Vecerová R, et al. Antifungal activity of silver nanoparticles against Candida spp. Biomaterials. 2009;30(31):6333-6340.

30. Humberto H Lara, Nilda V Ayala-Nuñez, LilianaIxtepan-Turrent, et al Mode of antiviral action of silver nanoparticles against HIV-1. Journal of Nanobiotechnology. 2010;8:1.

31. Rippere RA. Effects of paper on the performance of antibioticimpregnated discs. J Pharma Sci. 1978;67(3):367-371.

32. World Health Organization. WHO Model of essential medicines. Online source, World Health Organization. 2007.

33. Jonghoon Choi, Nam Sun Wang. Nanoparticles in Biomedical Applications and their Safety Concerns. 2011.

34. Jurgons R, C Seliger, A Hilpert, et al. Drug loaded magnetic nanoparticles for cancer therapy. J Phys Condens Matter. 2006;18(38):S2893-S2902.

35. Sun R, Chen R, Chung N, et al. Silver nanoparticles fabricated in Hepes buffer exhibit cytoprotective activities toward HIV-1 infected cells. Chem Commun. 2005;40:5059-5061.

36. Yang Z, Liu ZW, Allaker RP, et al. A review of nanoparticle functionality and toxicity on the central nervous system. $J R$ Soc Interface. 2010;7(Suppl 4):S411-422.

37. Golobič $\mathrm{M}$, Jemec A, Drobne $\mathrm{D}$, et al. Upon exposure to $\mathrm{Cu}$ nanoparticles, accumulation of copper in the isopod Porcellioscaber is due to the dissolved $\mathrm{Cu}$ ions inside the digestive tract", Environ $\mathrm{Sci}$ Technol. 2012;46(21):12112-12119.

38. Gleb B Sergeev. Cryochemistry of metal nanoparticles. Journal of Nanoparticle Research. 2003;5(5):529-537.

39. Pyatenko A, Shimokawa K, Yamaguchi M, et al. Synthesis of silver nanoparticles by laser ablation in pure water. Appl Phys A. 2004;79(4):803-806.

40. Siegel RW. Nanomaterials: Synthesis, properties and applications. Ann Rev Mater Sci. 1991;21:559-578.

41. Pratima Chauhan, Mini Mishra, Deepika Gupta. Potential Application of Nanoparticles as Antipathogens (Chapter 12). In: Ashutosh Tiwari \& Mikael Syväjärvi (Eds.), Advanced Materials for Agriculture, Food, and Environmental Safety, Scrivener Publishing LLC. 2014;pp.333-368.

42. Swihart MT. Vapour-phase synthesis of nanoparticles. Curr Opin Colloid Interface Sci. 2003;8(1):pp.127-133.

43. Krzysztof Szczepanowicz, Joanna Stefańska, Robert P Socha, et al. Preparation of Silver Nanoparticles Via Chemical Reduction And Their Antimicrobial Activity. Physicochem Probl Miner Process. 2010;45(2010):85-98.

44. Steve Lien-Chung Hsu, Rong-Tarng Wu. Preparation of Silver Nanoparticle with Different Particles Size for Low-Temperature Sintering. 2010 International Conference on Nanotechnology and Biosenors IPCBEE, IACSIT press, Singapore. 2011.

45. Sally D Solomon, Mozghan Bahadory, Aravindan VJ, et al. Synthesis and Study of Silver Nanoparticles. J Chem Educ. 2007;84(2):322.

46. Khanna PK, Narendra Singh, Shobhit Charan, et al. Synthesis and characterization of Ag/PVA nanocomposite by chemical reduction method. Materials Chemistry and Physics. 2005;93(1):117-121.

47. Khan Z,Al-Thabaiti SA, Obaid AY, et al. Preparation and characterization of silver nanoparticles by chemical reduction method. Colloids Surf B Biointerfaces. 2011;82(2):513-517. 
48. Ki Chang Song, Sung Min Lee, Tae Sun Park, Bum Suk Lee. Preparation of colloidal silver nanoparticles by chemical reduction method. Korean J Chem Eng. 2009;26(1):153-155.

49. Yu A Krutyakov, Kudrinskiy AA, A Yu Olenin, et al. Synthesis and Properties of Silver nanoparticles: advances and prospects. Russian chemical reviews. 2008;77(3):233-257.

50. Ankamwar B, Damle C, Ahmad A, et al. Biosynthesis of gold and silver nanoparticle using Emblica officinalis fruit extract, Their phase transfer and transmetallation in an organic solution. J Nanosci Nanotechnol. 2005;5(10):1665-1671.

51. Krishnaraj C, Jagan EG, Rajasekar S, et al. Synthesis of silver nanoparticles using Achlypha indica leaf extracts and its antibacterial activity against water borne pathogens. Colloids Surf B Biointerfaces. 2010;76(1):50-56.

52. Pantelis K, Andreas D, Vassilis Z, et al. Green synthesis and characterization of silver nanoparticles produced using Arbutus Unedo leaf extract. Materials Letters. 76(1):18-20.

53. Antariksh S, Tripathi RM, Fahmina Zafar, et al. Green synthesis of silver nanoparticles using aqueous solution of Ficusbenghalensisleaf extract and characterization of their antibacterial activity. Materials Letters. 2012;67(1):91-94.

54. Garima Singhal, Riju Bhavesh, Kunal Kasariya, et al. Biosynthesis of silver nanoparticles using Ocimum sanctum (Tulsi) leaf extract and screening its antimicrobial activity. $J$ Nanopart Res. 2011;13(7):2981-2988.

55. Zargar M, Hamid AA, Bakar FA, et al. Green Synthesis and Antibacterial Effect of Silver Nanoparticles Using Vitex Negundo L. Molecules. 2011;16(8):6667-6676.

56. Philip D, Unni C, Aromal SA, et al. Murraya Koenigii leaf-assisted rapid green synthesis of silver and gold nanoparticles. Spectrochim Acta A Mol Biomol Spectrosc. 2011;78(2):899-904.

57. Singh A, Jain D, Upadhyay MK, et al .Green Synthesis Of Silver Nanoparticles Using Argemone Mexicana Leaf Extract And Evaluation Of Their Antimicrobial Activities. Digest Journal of Nanomaterials and Biostructures. 2010;5(2):483-489.

58. Harekrishna Bar, Dipak Kr Bhui, Gobinda P Sahoo, et al. Green synthesis of silver nanoparticles using latex of Jatropha curcas. Colloids and Surfaces A: Physicochemical and Engineering Aspects. 2009;339(1-3):134-139.

59. Manish Dubey, Seema Bhadauriaa, Kushwah BS. Green Synthesis of Nanosilver Particles From Extract of Eucalyptus Hybrida (Safeda) Leaf. Digest Journal of Nanomaterials and Biostructures. 2009;4(3):537-543.

60. Mallikarjuna K, Narasimha G, Dillip GR, et al. Green synthesis of silver and palladium nanoparticles at room temperature using coffee and tea extract. Digest Journal of Nanomaterials and Biostructures. 2011;6(1):181-186.

61. Shikuo Li, Yuhua Shen, Anjian Xie, et al. Green synthesis of silver nanoparticles using Capsicum annuum L. extract. Green Chem. 2007;9:852-858.

62. Daizy Philip. Green synthesis of gold and silver nanoparticles using Hibiscus rosasinensis. Physica E. 2010;42(2010):1417-1424.

63. Sathishkumar M, Sneha K, Won SW, et al. Cinnamon zeylanicum bark extract and powder mediated green synthesis of nano-crystalline silver particles and its bactericidal activity. Colloids Surf B Biointerfaces. 2009;73(2):332-338.

64. Shashi Prabha Dubey, Manu Lahtinen, Mika Sillanpa. Green synthesis and characterizations of silver and gold nanoparticles using leaf extract of Rosa rugosa. Colloids and Surfaces A: Physicochemical and Engineering Aspects. 2010;364(1-3):34-41.

65. Pooley FD. Bacteria accumulate silver during leaching of sulphide ore minerals. Nature. 1982;296:642-643.
66. Nalenthiran P, Sambandam A, Govindarajan K, et al. Microbial synthesis of silver nanoparticles by Bacillus sp. J Nanopart Res. 2009;11(7):1811-1815.

67. Tanja Klaus, Ralph Joerger, Eva Olsson, et al. Silver-based crystalline nanoparticles, microbially fabricated. National Academy of Science U.S.A. 1999;96(24)13611-13614.

68. Absar Ahmad, Priyabrata Mukherjee, Satyajyoti Senapati, et al. Extracellular biosynthesis of silver nanoparticles using the fungus Fusarium oxysporium. Colloids and Surfaces B: Biointerfaces. 28(4):313-318.

69. Priyabrata Mukherjee, Absar Ahmad, Deendayal Mandal, et al. FungusMediated Synthesis of Silver Nanoparticles and Their Immobilization in the Mycelial Matrix: A Novel Biological Approach to Nanoparticle Synthesis. Nano Letters. 2001;1(10):515-519.

70. Gade AK, Bonde P, Ingle AP, Marcato PD, Durán N, et al. Exploitation of Aspergillus niger for Synthesis of Silver Nanoparticles. Journal of Biobased Materials and Bioenergy. 2(3): 243-247.

71. Meenal Kowshik, Shriwas Ashtaputre, Sharmin Kharrazi et al. Extracellular synthesis of silver nanoparticles by a silver-tolerant yeast strain MKY3. Nanotechnology. 2003;14(1):95-100.

72. Catalina Marambio-Jones, Eric MV Hoek A review of the antibacterial effects of silver nanomaterials and potential implications for human health and the environment. Journal of Nanoparticle Research. 2010;12(5):1531-1551.

73. AshaRani PV, Low Kah Mun G, Hande MP, Valiyaveettil S Cytotoxicity and Genotoxicity of Silver Nanoparticles in Human Cells. ACS Nano. 2009;3(2):279-290.

74. Ivan Sondi, Branka Salopek-Sondi Silver nanoparticles as antimicrobial agent: a case study on E. coli as a model for Gram-negative bacteria. $J$ Colloid Interface Sci. 2004;275(1):177-182.

75. Amro AN, Lakshmi PK, Kapila WM et al. High-Resolution Atomic Force Microscopy Studies of the Escherichia coli Outer Membrane: Structural Basis for Permeability. Langmuir. 2000;16(6):2789-2796.

76. Ruparelia J, Chatteriee A, Duttagupta $\mathrm{S}$ et al. Strain specificity in antimicrobial activity of silver and copper nanoparticles. Acta Biomater. 2008;4(3):707-716.

77. Thakur DS, Peeyush K, Kumar P Current concepts and newer developments in cancer. International Journal of Pharmaceutical Sciences Review and Research. 2010;3(2):85-89.

78. Ferari M Cancer nanotechnologies: Opportunities and challenges. Nat Rev Cancer. 2005;5(3):161-71.

79. Roy I, Ohulchanskyy TY, Pudavar HE et al. Ceramic-based nanoparticles entrapping water-insoluble photosensitizing anticancer drugs: A novel drug-carrier system for photodynamic therapy. $J \mathrm{Am}$ Chem Soc. 2003;125(26):7860-7865.

80. Yezhelyev MV, Gao X, Xing Y et al. Emerging use of nanoparticles in diagnosis and treatment of breast cancer. Lancet Oncol. 2006;7(8):657-667.

81. Mritunjai Singh, Shinjini Singh, Prasada S et al. Nanotechnology In Medicine And Antibacterial Effect of Silver Nanoparticles. Digest Journal of Nanomaterials and Biostructures. 2008;3(3): 115-122.

82. Kim JS, Kuk E, Yu KN et al. Antimicrobial effects of silver nanoparticles. Nanomedicine. 2007;3(1):95-101.

83. Arora S, Jain J, Rajwade JM, Paknikar KM Cellular Responses Induced by Silver Nanoparticles: In Vitro Studies. Toxicol Lett. 2008;179(2):93-100.

84. Bamrungsap S, Zhao Z, Chen T et al. Nanotechnology in therapeutics a focus on Nanoparticles as a Drug Delivery System. Nanomedicine. 2012;7(8):1253-1271. 
85. Junghanns JU, Müller RH Nanocrystal technology, drug delivery and clinical applications. Int J Nanomedicine. 2008;3(3):295-310.

86. Ahn SJ, Lee SJ, Kook JK, Lim BS Experimental antimicrobial orthodontic adhesives using nanofillers and silver nanoparticles. Dent Mater. 2009;25(2):206-213.

87. Jitendra Prasad, Mathuria Nanoparticles in tuberculosis diagnosis, treatment and prevention: A hope for the future. Digest Journal Nanomaterials Biostructure. 2009;4(2):309-312.

88. Xiliang Luo, Aoife Morrin, Anthony J Killard et al. Smyth Application of Nanoparticles in Electrochemical Sensors and Biosensors. Electroanalysis. 2006;18(4):319-326.

89. Ravishankar Rai V, Jamuna Bai A Nanoparticles and their potential application as antimicrobials. Science against microbial pathogens: communicating current research and technological advances. 2015;197-209.

90. Chaloupka K, Malam Y, Seifalian AM Nanosilver as a new generation of nanoproduct in biomedical applications. Trends Biotechnol. 2010;28(11):580-588.

91. http://www.accessdata.fda.gov/cdrh_docs/pdf5/K053627.pdf

92. http://www.accessdata.fda.gov/cdrh_docs/pdf5/K050032.pdf

93. http://www.accessdata.fda.gov/cdrh_docs/pdf2/K022483.pdf

94. http://www.accessdata.fda.gov/cdrh_docs/pdf2/K023609.pdf

95. Atiyeh BS, Costagliola M, Hayek SN, Dibo SA Effect of silver on burn wound infection control and healing: review of the literature. Burns. 2007;33(2):139-148.

96. Qin Y Silver containing alginate fibres and dressings. Int Wound J. 2005;2(2):172-176.

97. Hermans MH Silver containing dressings and the need for evidence. $\mathrm{Am}$ J Nurs. 2006;106(12):60-68.

98. Hussain S, Ferguson C Best evidence topic report. Silver sulphadiazine cream in burns. Emerg Med J. 2006;23(12):929-932.

99. Pirnay JP, De Vos D, Cochez C et al. Molecular epidemiology of Pseudomonas aeruginosacolonization in a burn unit: Persistence of a multidrug resistant clone and a silver sulfadiazine resistant clone. J Clin Microbiol. 2003;41(3):1192-1202.

100. Gupta A, Phung LT, Taylor DE, Silver S Diversity of silver resistance genes in IncH incompatibility group plasmids. Microbiology. 2001;147:3393-3402.

101. Govender R, Phulukdaree A, Gengan RM et al. Silver nanoparticles of Albiziaadianthifolia: the induction of apoptosis in human lung carcinoma cell line. J Nanobiotechnology. 2013;11:5.

102. Patra CR, Mukherjee S, Kotcherlakota R Biosynthesized silver nanoparticles: a step forward for cancer theranostics? Nanomedicine. 2014;9(10):1445-1448.

103. Ge L, Li Q, Wang M, Ouyang J et al. Nanosilver particles in medical applications: synthesis, performance, and toxicity. Int J Nanomedicine. 2014;9:2399-2407.

104. Yu-Fen Huang, Huan-Tsung Chang, Weihong Tan Cancer Cell Targeting Using Multiple Aptamers Conjugated on Nanorods. Anal Chem. 2008;80(3):567-572.

105. Wu Y, Loper A, Landis E et al. The role of biopharmaceutics in the development of a clinical nanoparticle formulation of MK0869: A beagle dog model predicts improved bioavailability and diminished food effect on absorption in human. Int J Pharm. 2004;285(1-2):135-146.

106. Gojova A, Guo B, Kota RS et al. Induction of inflammation in vascular endothelial cells bymetal oxide nanoparticles: effect of particle composition. Environ Health Perspect. 2007;115(3):403-409.

107. Elechiguerra JL, Burt JL, Morones JR et al. Interaction of silver nanoparticles with HIV-1. J Nanobiotechnol. 2005;3:6. 